\title{
CARBON-BASED SOLID ACID CATALYZED SYNTHESIS OF POLYHYDROQUINOLINE DERIVATIVES VIA HANTZSCH REACTION UNDER SOLVENT-FREE CONDITIONS
}

\author{
ABOLGHASEM DAVOODNIA', AMIR KHOJASTEHNEZHAD
}

Department of Chemistry, Mashhad Branch, Islamic Azad University, Mashhad, Iran

(Received: May 3, 2012 - Accepted: July 24, 2012)

\begin{abstract}
An easy method for the synthesis of polyhydroquinoline derivatives via one-pot four-component Hantzsch condensation of dimedone, aryl aldehydes, ethyl acetoacetate and ammonium acetate in the presence of a catalytic amount of carbon-based solid acid (CBSA) in solvent-free conditions is described. The main advantages of the present approach are relatively short reaction times, high product yields, clean reaction profiles, simple experimental and work-up procedure.
\end{abstract}

Keywords: polyhydroquinoline derivatives, carbon-based solid acid, heterogeneous catalysis, solvent-free conditions.

\section{INTRODUCTION}

In recent years, much attention has been devoted to the synthesis of polyhydroquinoline compounds due to their diverse therapeutic and pharmacological properties, such as vasodilator, antitumor, bronchodilator, antiartherosclerotic, geroprotective and hepatoprotective activity ${ }^{1-6}$. Particularly, 4-aryl-1,4-dihydropyridines are well known as calcium channel blockers and have emerged as one of the most important class of drugs for the treatment of cardiovascular diseases ${ }^{7}$. Cardiovascular agents such as nifedipine, nicardipine, amlodipine, and other related derivatives are dihydropyridyl compounds, which are effective for the treatment of hypertension ${ }^{8-10}$. For these reasons, polyhydroquinoline compounds not only have attracted the attention of chemists to synthesize but also represent an interesting research challenge. However, despite their importance from a pharmacological, and synthetic point of view, comparatively very few methods for their preparation have been reported. Generally, 1,4-dihydropyridines are synthesized by the Hantszch condensation method, which involves cyclocondensation of aldehyde, $\beta$-ketoester and ammonia either in acetic acid at room temperature or refluxing in alcohol for a long time ${ }^{7,11}$. However, these methods suffer from several drawbacks such as long reaction time, an excess of organic solvent, lower product yields, and harsh refluxing conditions. Therefore, it is necessary to develop more efficient and versatile methods for the preparation of these compounds.

Recently, a number of improved methods have been reported in the literature for the synthesis of polyhydroquinolines which involve the use of microwave irradiation ${ }^{12}$, solar thermal energy ${ }^{13}$, grinding ${ }^{14}$, and also using various catalysts such as ionic liquid ${ }^{15}$, metal triflates ${ }^{16}$, HY-Zeolite ${ }^{17}$, montmorillonite $\mathrm{K}-10^{18}$, cerium(IV) ammonium nitrate ${ }^{19}, \mathrm{HClO}_{4}-\mathrm{SiO}_{2}{ }^{20}$, molecular iodine ${ }^{21}, \mathrm{Yb}(\mathrm{OTf})_{3}{ }^{22}$, and nickel nano particle ${ }^{23}$. However, most of these methodologies suffer from disadvantages such as unsatisfactory yields, toxic organic solvents, harsh reaction conditions, long reaction times and the use of relatively expensive reagents. These finding prompted us towards further investigation in search for a new catalyst, which will carry out the synthesis of polyhydroquinoline derivatives under simpler experimental set up and ecofriendly conditions.

Using solid acid catalysts have some advantages such as ease of products separation, recycling of the catalyst and environmental acceptability as compared to liquid acid catalysts ${ }^{24}$. Carbon-based solid acid (CBSA) catalyst has many advantages. It is insoluble in common organic solvents, causes low corrosion, and shows environmental acceptability. Also the products could be easily separated from the reaction mixture and the catalyst is recoverable without significant decreasing its activity. Therefore, it can be successfully used instead of sulfuric acid as catalyst ${ }^{25,26}$. To the best of our knowledge, there is no report in the literature on the use of CBSA as catalyst for the synthesis of polyhydroquinoline derivatives. On the other hand, solvent-free conditions are especially important for providing an eco-friendly system. The number of publications reporting solvent-free conditions for the heterocyclic synthesis has increased rapidly in recent years ${ }^{27}$.

Therefore, due to the increasing demand in modern organic processes for avoiding expensive purification, and in continuation of our previous works on the applications of reusable catalysts in the synthesis of organic compounds
${ }^{28-36}$, we report herein a new and efficient synthesis of polyhydroquinoline derivatives using a one-pot, four-component Hantszch condensation of dimedone, aryl aldehydes, ethyl acetoacetate and ammonium acetate using a catalytic amount of CBSA under solvent-free conditions (Scheme 1).

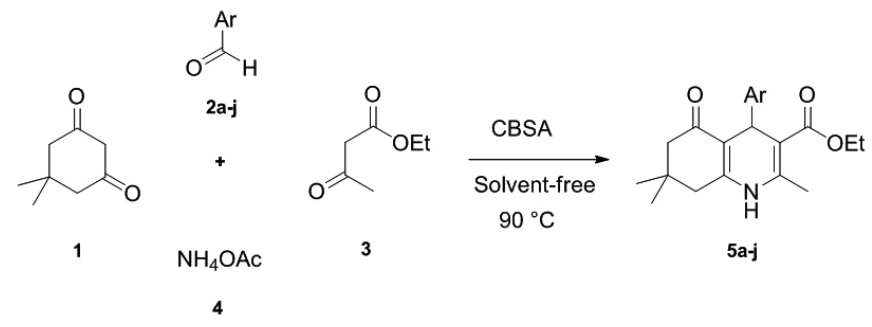

Scheme 1. CBSA catalyzed synthesis of polyhydroquinoline derivatives.

\section{EXPERIMENTAL}

All chemicals were available commercially and used without additional purification. Melting points were recorded on a Stuart SMP3 melting point apparatus. The IR spectra were obtained using a Tensor 27 Bruker spectrophotometer as $\mathrm{KBr}$ disks. The ${ }^{1} \mathrm{H}$ NMR (500 MHz) spectra were recorded with a Bruker DRX500 spectrometer.

\section{Preparation of CBSA}

The CBSA was prepared according to the reported procedure by Hara and co-workers ${ }^{25}$. Naphthalene $(20 \mathrm{~g})$ was heated in concentrated sulfuric acid $(>96 \%, 200 \mathrm{~mL})$ at $250{ }^{\circ} \mathrm{C}$ under a flow of $\mathrm{N}_{2}$. After heating for $15 \mathrm{~h}$, excess sulfuric acid was removed from the dark brown tar by vacuum distillation at $250{ }^{\circ} \mathrm{C}$ for $5 \mathrm{~h}$, which resulted in a black solid. The solid was then ground to a powder and was washed repeatedly in boiling water until impurities such as sulfate ions were no longer detected in the wash water. The density of the $\mathrm{SO}_{3} \mathrm{H}$ group was measured using $\mathrm{NaOH}(0.01 \mathrm{~mol} / \mathrm{L})$ as titrant by acidbase potentiometric titration. The amount of $\mathrm{SO}_{3} \mathrm{H}$ attached to the polycyclic aromatic carbon was $2.79 \mathrm{mmol} / \mathrm{g}$.

General procedure for the synthesis of polyhydroquinoline derivatives 5a-j using CBSA as catalyst

A mixture of dimedone $\mathbf{1}(1 \mathrm{mmol})$, aryl aldehyde $\mathbf{2 a - j}(1 \mathrm{mmol})$, ethyl acetoacetate $3(1 \mathrm{mmol})$, ammonium acetate $4(1.2 \mathrm{mmol})$ and CBSA $(0.02$ g) was heated on the oil bath at $90{ }^{\circ} \mathrm{C}$ for $18-35 \mathrm{~min}$. The reaction was monitored by TLC. Upon completion, the reaction mixture was cooled to room temperature and then hot ethanol was added. The catalyst was insoluble in hot ethanol and it could therefore be recycled by a simple filtration. The crude product was collected from the filtrate after cooling to room temperature and recrystallized from ethanol to give compounds $\mathbf{5 a}$-j in high yields.

Recycling and reusing of the catalyst

Due to the fact that the catalyst was insoluble in hot ethanol, it could 
therefore be recycled by a simple filtration. The separated catalyst was washed with cold ethanol, dried at $60^{\circ} \mathrm{C}$ under vacuum for $1 \mathrm{~h}$ and reused in the model reaction. The catalyst could be used at least three times without significant loss of activity.

\section{RESULTS AND DISCUSSION}

The catalyst was prepared according to the literature method ${ }^{25}$. At the outset, the synthesis of compound 5a was selected as a model reaction to optimize the reaction conditions. The reaction was carried out by heating a mixture of dimedone $\mathbf{1}(1 \mathrm{mmol})$, benzaldehyde $\mathbf{2 a}(1 \mathrm{mmol})$, ethyl acetoacetate $3(1 \mathrm{mmol})$, ammonium acetate $4(1.2 \mathrm{mmol})$ in the presence of CBSA under various conditions.

The CBSA catalyst is amorphous carbon consisting of polycyclic aromatic carbon sheets with attached $\mathrm{SO}_{3} \mathrm{H}$ groups that functions as a strong solid acid with a high density of acid sites and therefore can promote the reactions. As can be seen from Table 1, the efficiency of the reaction is affected mainly by the amount of CBSA. No product was obtained in the absence of the catalyst even after $180 \mathrm{~min}$ (entry 1), but we were pleased to see that the synthesis of compound 5a was efficiently catalyzed by CBSA (Entries 2-6). The best catalytic activity of CBSA was optimized to be $0.02 \mathrm{~g}$ (Entry 4 ) and any excess of the catalyst, beyond this proportion, did not show any significant increase in the conversion and yield (Entries 5 and 6).

Table 1. Effect of the amounts of CBSA on the model reaction ${ }^{a}$

\begin{tabular}{|c|c|c|c|}
\hline Entry & Catalyst $(\mathrm{g})$ & Time $(\min )$ & ${\text { Yield }(\%)^{b}}^{b}$ \\
\hline 1 & None & 180 & None \\
\hline 2 & 0.01 & 25 & 69 \\
\hline 3 & 0.015 & 25 & 83 \\
\hline 4 & 0.02 & 25 & 92 \\
\hline 5 & 0.03 & 25 & 93 \\
\hline 6 & 0.05 & 25 & 93 \\
\hline
\end{tabular}

${ }^{a}$ Reaction conditions: $1 \mathrm{mmol}$ dimedone $\mathbf{1}, 1 \mathrm{mmol}$ benzaldehyde 2a, 1 mmol ethyl acetoacetate $\mathbf{3}$, and $1.2 \mathrm{mmol}$ ammonium acetate $\mathbf{4}$ at $90^{\circ} \mathrm{C}$.

${ }^{b}$ The yields were calculated based on benzaldehyde and refer to the pure isolated product.

The same model reaction in presence of $0.02 \mathrm{~g}$ of the catalyst was carried out at different temperatures in solvent-free conditions and also in different solvents to assess the effect of temperatures and solvent on the reaction yield. As shown in Table 2, the yields of the reaction under solvent-free conditions were greater and the reaction times were generally shorter than the conventional methods. The best result was obtained at $90{ }^{\circ} \mathrm{C}$ for 25 min under solvent-free conditions. Increasing the reaction time or temperature did not improve the yield. Subsequently, therefore, all reactions were carried out at $90{ }^{\circ} \mathrm{C}$ in the presence of $0.02 \mathrm{~g} \mathrm{CBSA}$ under solvent-free conditions.

Table 2. Synthesis of compound 5a in the presence of $0.02 \mathrm{~g} \mathrm{CBSA}^{a}$

\begin{tabular}{|c|c|c|c|c|}
\hline Entry & Solvent & $\begin{array}{c}\text { Temperature } \\
\left({ }^{\circ} \mathrm{C}\right)\end{array}$ & Time (h) & Yield $(\%)^{b}$ \\
\hline 1 & EtOH & Reflux & 3 & 83 \\
\hline 2 & $\mathrm{MeOH}$ & Reflux & 3 & 72 \\
\hline 3 & $\mathrm{CH}_{3} \mathrm{CN}$ & Reflux & 3 & 65 \\
\hline 4 & $\mathrm{CH}_{2} \mathrm{Cl}_{2}$ & Reflux & 3 & 60 \\
\hline 5 & Solvent-Free & 60 & $25(\min )$ & 58 \\
\hline 6 & Solvent-Free & 70 & $25(\min )$ & 71 \\
\hline 7 & Solvent-Free & 80 & $25(\min )$ & 83 \\
\hline 8 & Solvent-Free & 90 & $25(\min )$ & 92 \\
\hline 9 & Solvent-Free & 100 & $25(\mathrm{~min})$ & 92 \\
\hline 10 & Solvent-Free & 120 & $25(\mathrm{~min})$ & 93 \\
\hline
\end{tabular}

${ }^{a}$ Reaction conditions: $1 \mathrm{mmol}$ dimedone $\mathbf{1}, 1 \mathrm{mmol}$ benzaldehyde $\mathbf{2 a}, 1$ mmol ethyl acetoacetate $\mathbf{3}$, and $1.2 \mathrm{mmol}$ ammonium acetate $\mathbf{4}$.

${ }^{b}$ The yields were calculated based on benzaldehyde and refer to the pure isolated product.

After optimizing the conditions, we next examined the generality of these conditions to other substrates using several aryl aldehydes $\mathbf{2 a - j}$. The results are summarized in Table 3 . It could be seen that CBSA as environmentally benign solid acid catalyzed the condensation of $\mathbf{1}, \mathbf{2 a - j}, \mathbf{3}$, and $\mathbf{4}$ at $90{ }^{\circ} \mathrm{C}$. On the other hand, easy separation of obtained products from the catalyst makes this method useful for the synthesis of polyhydroquinolines. As indicated in Table 3 , in all cases the reaction gives the products in high yields under solvent-free conditions and prevents problems which many associate with solvent use such as cost, handling, safety and pollution.

Table 3. CBSA catalyzed synthesis of polyhydroquinoline derivatives 5a$\mathbf{j}^{\alpha}$

\begin{tabular}{|c|c|c|c|c|c|c|}
\hline \multirow{2}{*}{$\begin{array}{l}\text { En- } \\
\text { try }\end{array}$} & \multirow{2}{*}{$\mathrm{Ar}$} & \multirow{2}{*}{ Products $^{b}$} & \multirow{2}{*}{$\begin{array}{l}\text { Time } \\
(\mathrm{min})\end{array}$} & \multirow{2}{*}{$\begin{array}{l}\text { Yields } \\
(\%)^{c}\end{array}$} & \multicolumn{2}{|c|}{ m.p. $\left({ }^{\circ} \mathrm{C}\right)$} \\
\hline & & & & & Found & Reported \\
\hline 1 & $\mathrm{C}_{6} \mathrm{H}_{5}$ & & 25 & 92 & $\begin{array}{l}202- \\
204\end{array}$ & $202-204^{22}$ \\
\hline 2 & 4- $\mathrm{BrC}_{6} \mathrm{H}_{4}$ & & 30 & 90 & $\begin{array}{l}252- \\
254\end{array}$ & $253-255^{22}$ \\
\hline 3 & 4- $\mathrm{ClC}_{6} \mathrm{H}_{4}$ & & 20 & 94 & $\begin{array}{l}244- \\
246\end{array}$ & $245-247^{23}$ \\
\hline 4 & 4- $-\mathrm{FC}_{6} \mathrm{H}_{4}$ & & 30 & 90 & $\begin{array}{l}184- \\
186\end{array}$ & $184-186^{22}$ \\
\hline 5 & $3-\mathrm{HOC}_{6} \mathrm{H}_{4}$ & & 28 & 88 & $\begin{array}{l}218- \\
221\end{array}$ & $218-220^{23}$ \\
\hline 6 & 4- $\mathrm{HOC}_{6} \mathrm{H}_{4}$ & & 32 & 87 & $\begin{array}{l}230- \\
232\end{array}$ & $231-233^{23}$ \\
\hline 7 & $4-\mathrm{MeOC}_{6} \mathrm{H}_{4}$ & & 35 & 88 & $\begin{array}{l}255- \\
258\end{array}$ & $257-259^{22}$ \\
\hline 8 & 4- $\mathrm{MeC}_{6} \mathrm{H}_{4}$ & & 35 & 89 & $\begin{array}{c}260- \\
263\end{array}$ & $261-263^{23}$ \\
\hline 9 & $3-\mathrm{O}_{2} \mathrm{NC}_{6} \mathrm{H}_{4}$ & & 25 & 91 & $\begin{array}{l}178- \\
181\end{array}$ & $174-176^{23}$ \\
\hline 10 & $4-\mathrm{O}_{2} \mathrm{NC}_{6} \mathrm{H}_{4}$ & & 18 & 95 & $\begin{array}{l}244- \\
246\end{array}$ & $244-246^{23}$ \\
\hline
\end{tabular}

${ }^{a}$ Reaction conditions: $1 \mathrm{mmol}$ dimedone $\mathbf{1}, 1 \mathrm{mmol}$ aryl aldehyde $\mathbf{2} \mathbf{a}-\mathbf{j}, 1$ mmol ethyl acetoacetate $3,1.2 \mathrm{mmol}$ ammonium acetate 4 , and $0.02 \mathrm{~g} \mathrm{CBSA}$ at $90^{\circ} \mathrm{C}$ under solvent-free conditions.

${ }^{b}$ All the products were characterized by IR spectral data and comparision of their melting points with those of authentic samples. Also, the structures of some products were confirmed by ${ }^{1} \mathrm{H}$ NMR spectral data.

${ }^{c}$ The yields were calculated based on aryl aldehyde and refer to the pure isolated product. 
It is essential for the solid acid to maintain strong acidity even after recycling. Thus, the reusability of the catalyst was also investigated. For this purpose, the same model reaction was again studied under optimized conditions. The catalyst was recovered according to the procedure mentioned in experimental section and reused for a similar reaction. As shown in Fig. 1 , the catalyst could be used at least three times without significant loss of activity. In this catalyst, $\mathrm{SO}_{3} \mathrm{H}$ groups have been covalently bound to the polycyclic aromatic carbon sheets. Thus, the catalyst has high stability and could behave as recyclable solid catalyst without the danger of leaching that is observed in most of supported catalysts. However, the slight reduction of catalytic activity of the catalyst after recycling is probably due to the blockage a few part of active sites in the catalyst.

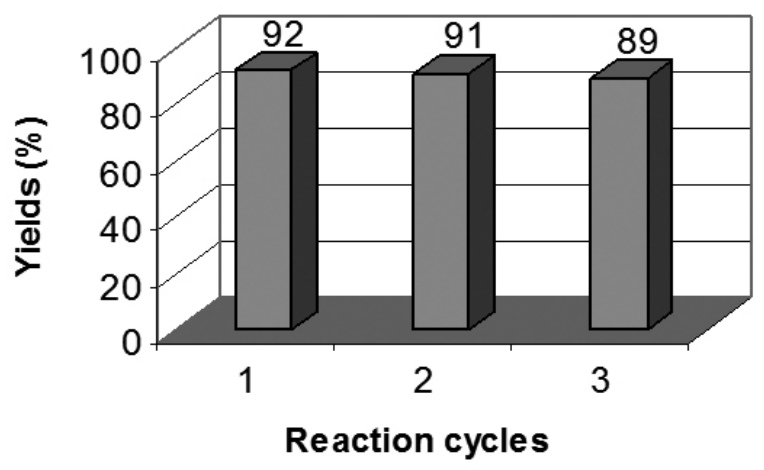

Fig. 1. Reusability of the catalyst for model reaction.

\section{CONCLUSIONS}

In conclusion, we have developed a simple new catalytic method for the synthesis of polyhydroquinoline derivatives via one-pot four-component Hantzsch condensation of dimedone, aryl aldehydes, ethyl acetoacetate and ammonium acetate in the presence of CBSA as an efficient, reusable, and green heterogeneous catalyst under solvent-free conditions. Some attractive features of this protocol are high yields, simple procedure, relatively short reaction times, easy work-up, high catalytic activity and recyclability and reusability of the catalyst. The catalyst can be used at least three times without substantial reduction in its catalytic activity. We believe this applicability of CBSA with mentioned advantages makes our method superior over other reported methods to synthesis of polyhydroquinoline derivatives.

\section{ACKNOWLEDGEMENT}

The authors express their gratitude to the Islamic Azad University, Mashhad Branch for its financial support

\section{REFERENCES}

1. F. Bossert, H. Meyer and E. Wehinger, Angew. Chem. Int. Ed. Engl. 20 (1981) 762 .

2. H. Nakayama, Y. Kasoaka, Heterocycles 42 (1996) 901.

3. Y. Sawada, H. Kayakiri, Y. Abe, T. Mizutani, N. Inamura, M. Asano, C. Hatori, I. Aramori, T. Oku and H. Tanak, J. Med. Chem. 47 (2004) 2853.

4. T. Godfaid, R. Miller and M. Wibo, Pharmacol Rev. 38 (1986) 321.

5. R. Mannhold, B. Jablonka, W. Voigdt, K. Schoenafinger and K. Schravan, Eur. J. Med. Chem. 27 (1992) 229.

6. R. Shan, C. Velazquez and E. E. Knaus, J. Med. Chem. 47 (2004) 254.

7. B. Love, K. M. Snader, J. Org. Chem. 30 (1965) 1914.

8. F. R. Buhler, W. Kiowski, J. Hypertens. 5 (1987) S3.

9. J. L. Reid, P. A. Meredith and F. Pasanisi, J. Cardiovasc. Pharmacol. 7 (1985) S18.

10. H. Nakayama, Y. Kasoaka, Heterocycles 42 (1996) 901.

11. A. Hantzsch, Ber. Dtsch. Chem. Ges. 21 (1888) 942.

12. S. J. Tu, J. F. Zhou, X. Deng, P. J. Cai, H. Wang and J. C. Feng, Chin. J. Org. Chem. 21 (2001) 313.

13. R. A. Mekheimer, A. A. Hameed and K. U. Sadek, Green. Chem. 10 (2008) 592.
14. S. Kumar, P. Sharma, K. K. Kapoor and M. S. Hundal, Tetrahedron 64 (2008) 536.

15. X. Y. Zhang, Y. Z. Li, X. S. Fan, G. R. Qu, X. Y. Hu and J. J. Wang, Chin. Chem. Lett. 17 (2006) 150.

16. L. M. Wang, J. Sheng, L. Zhang, J. W. Han, Z. Y. Fan, H. Tian and C. T. Qian, Tetrahedron 61 (2005) 1539.

17. B. Das, B. Ravikanth, R. Ramu and V. B. Rao, Chem. Pharm. Bull. 54 (2006) 1044.

18. G. Song, B. Wang, X. Wu, Y. Kang and L. Yang, Synth. Commun. 35 (2005) 2875.

19. C. S. Reddy, M. Raghu, Chin. Chem. Lett. 19 (2008) 775.

20. M. Maheswara, V. Siddaiah, G. L. V. Damu and C. V. Rao, Arkivoc 2 (2006) 201

21. S. Ko, M. N. V. Sastry, C. Lin and C. F. Yao, Tetrahedron Lett. 46 (2005) 5771.

22. L. M. Wang, J. Sheng, L. Zhang, J. W. Han, Z. Y. Fan, H. Tian and C. T. Qian, Tetrahedron 61 (2005) 1539.

23. S. B. Sapkal, K. F. Shelke, B. B. Shingate and M. Shingare, Tetrahedron Lett. 50 (2009) 1754.

24. T. Okuhara, Chem, Rev. 102 (2002) 3641.

25. M. Hara, T. Yoshida, A. Takagaki, T. Takata, J. N. Kondo, S. Hayashi and K. Domen, Angew. Chem. Int. Ed. 43 (2004) 2955.

26. L. Zhou, K. Liu, W. M. Hua, Y. H. Yue and Z. Gao, Chin. J. Chem. 30 (2009) 196.

27. M. A. P. Martins, C. P. Frizzo, D. N. Moreira, L. Buriol and P. Machado, Chem. Rev. 109 (2009) 4140.

28. A. Davoodnia, M. Roshani, S. H. Malaeke and M. Bakavoli, Chin. Chem. Lett. 19 (2008) 525.

29. A. Davoodnia, M. M. Heravi, L. Rezaei-Daghigh and N. TavakoliHoseini, Chin. J. Chem. 28 (2010) 429.

30. A. Davoodnia, S. Allameh, A. R. Fakhari and N. Tavakoli-Hoseini, Chin Chem. Lett. 21 (2010) 550.

31. A. Davoodnia, M. M. Heravi, Z. Safavi-Rad and N. Tavakoli-Hoseini, Synth. Commun. 40 (2010) 2588.

32. A. Davoodnia, Asian. J. Chem. 22 (2010) 1595

33. N. Tavakoli-Hoseini, A. Davoodnia, Asian J. Chem. 22 (2010) 7197.

34. A. Davoodnia, A. Tavakoli-Nishaburi and N. Tavakoli-Hoseini, Bull. Korean. Chem. Soc. 32 (2011) 635.

35. M. Zeinali-Dastmalbaf, A. Davoodnia, M. M. Heravi, N. TavakoliHoseini, A. Khojastehnezhad and H. A. Zamani, Bull. Korean Chem. Soc. 32 (2011) 656.

36. A. Khojastehnezhad, A. Davoodnia, M. Bakavoli, N. Tavakoli-Hoseini and M. Zeinali-Dastmalbaf, Chin. J. Chem. 29 (2011) 297. 